\title{
Transient Tooth Discoloration After Periodontal Instrumentation of an Aggressive Periodontitis. A Case Report
}

\author{
Julio C Rincon A*, Zahida Oakley*, Paul Abbott ${ }^{\dagger}$ \\ *Department of Periodontology and Implant Dentistry. School of Dentistry The \\ University of Western Australia. Perth, Western Australia.
†Department of Endodontics. School of Dentistry The University of Western Australia. Perth, Western Australia.

\begin{abstract}
Introduction: Transient tooth discoloration (TTD) is an endodontic condition associated with dental traumatic events. To the best of the authors' knowledge, this is the first case report of transient coronal discoloration of the two upper permanent central incisors following periodontal instrumentation of root surfaces affected by aggressive periodontitis. The initial case presentation and multi-disciplinary periodontal, endodontic, and orthodontic management are described.
\end{abstract}

Case Presentation: A 17 year-old male was referred from the Orthodontics Department to the Periodontics Department at the Oral Health Center of Western Australia. A localized aggressive periodontitis was diagnosed. After meticulous periodontal debridement of the mid-root and apical root portions of two upper central incisors, TTD was noted five months later. The diagnosis, case management and biological explanations for the unique presentation of these conditions are discussed.

Conclusion: Transient tooth discoloration may be caused by trauma from periodontal instrumentation. This is the first report of TTD in an aggressive periodontitis case. Proper diagnosis and management of this particular condition is important to protect the integrity of the pulp in affected teeth. This case report opens the possibility of the presence of transient tooth discoloration originating from causes other than traumatic luxation or intra-alveolar root fractures of teeth.

\section{Key Words:}

Aggressive periodontitis, Endo-perio, Diagnosis, Scaling root planning.

\section{Background}

Transient tooth discoloration (TTD) has been described in the dental literature as a clinical finding due to intra-pulp hemorrhage subsequent to dental trauma, after avulsion and replantation, and auto-transplantation of incisors in dog. ${ }^{1}$ These transient coronal colour changes are also associated with transient apical breakdown after luxation injuries in primary or permanent teeth. ${ }^{2}$ Variable pulp sensibility responses also occur after a traumatic event. ${ }^{3}$

All reported cases and studies describing TTD are associated with transient apical breakdown of the pulp from luxation injuries, for example, lateral luxation, extrusion, subluxation and concussion. ${ }^{3-7}$ A recent study also reported transient tooth discoloration after intra-alveolar root fractures. ${ }^{8}$

The authors are not aware of any report of TTD after periodontal debridement of root surfaces. Hence, this is the first report of TTD associated with periodontal instrumentation of root surfaces in a localized aggressive periodontitis case.

\section{Clinical Presentation}

A 17 year-old male was referred from the Orthodontics Department to the Periodontics Department at the Oral Health Center of Western Australia, in Perth in July 2010. The patient was not aware of any periodontal problems but the Orthodontist identified periodontal pocketing and referred the case for periodontal 
assessment and management (Fig. 1). The patient was born in Eritrea, East Africa with a black African racial background and came to Perth, Australia at an early age.

Periodontal probing revealed localized pocketing with a range of 7 to $9 \mathrm{~mm}$ associated with his \#3, \#8, \#9, \#14, \#19, \#23 and \#24 with attachment loss of 5 to 7 $\mathrm{mm}$ (Fig. 2). The upper central incisors had moderate to severe crowding and a $2 \mathrm{~mm}$ diastema. The O'Leary bacterial plaque score was $90 \%$. Despite this plaque score, a diagnosis of localized severe aggressive periodontitis was assigned, based on: 1 . The amount of sub-gingival calculus as this was not consistent with the severity of disease, 2. This patient did not have any systemic conditions, 3 . The severity and distribution of disease (Incisive /molar pattern with 70\% and 50\% bone loss) 4 . Patient's age (17 year-old), and 5. The rapid periodontal destruction (Figs. 3, 4, and 5). ${ }^{9,10}$

\section{Clinical Management}

A periodontal treatment plan was organised in July 2010 and consisted of: Systemic Phase: Prescription of red and white blood cell counts and glucose blood levels to discard any systemic condition. An Initial periodontal phase of treatment: with oral hygiene instructions followed by periodontal debridement combined with adjunct antimicrobials. ${ }^{11,12}$ Review-reassessment Phase: Six to eight weeks after initial phase complexion to assess the response to the initial phase of treatment. The possibility of a surgical/regenerative periodontal treatment phase: for sites with advanced attachment loss and angular bone defects. A supportive periodontal treatment phase: Review recalls every three months with the chance to extend to six months if the periodontal condition is controlled.

As the medical history and blood tests did not reveal any relevant medical condition, periodontal treatment was commenced in September 2010 with an initial periodontal phase of treatment, oral hygiene instructions, followed by periodontal debridement with adjunct Azithromycin, once a day for three days after appointment one. The second appointment for periodontal debridement was in late September 2010 followed by a combination of Amoxicillin and Metronidazole for 7 days (at the completion of the initial phase debridement). A periodontal review was done in November 2010 and, despite poor oral hygiene with O’Leary's plaque index score of $100 \%$, the periodontal pocketing had reduced slightly. A reduction in the diastema between \#8 and \#9 was also noticed (Fig. 6). The patient's oral hygiene measures were fully reviewed and no periodontal debridement was done at that time. The patient was asked to return for a further review in February 2011. At that appointment, the patient complained of severe grey/rosy discoloration of \#8 and \#9 (Figs. 7 and 8). He was asked whether he had experienced any impact trauma on these teeth but he did not report any.

The patient was referred to the Endodontics Department for assessment of the condition of the pulps in \#8 and \#9. The endodontic assessment revealed normal responses to $\mathrm{CO}_{2}$ and electric pulp sensibility tests. There were no symptoms and no radiographic signs of any periapical changes. The pulps and periapical tissues were diagnosed as being clinically normal for both teeth. The grey/rosy discoloration was provisionally diagnosed as TTD associated with transient breakdown of the pulp following the periodontal treatment. It was recommended to monitor the pulp conditions and the color of both central incisors and to continue periodontal treatment as required. 


\section{Clinical Outcomes}

In March 2011, periodontal review revealed improvement of both the oral hygiene and periodontal pocketing. The tooth discoloration persisted and the pulps continued to respond normally to both the $\mathrm{CO}_{2}$ and electric pulp tests.

In August 2011, the periodontal condition was under control with complete resolution of periodontal pocketing associated with \#3, \#8, \#9, \#14, \#19, \#23 and \#24. TTD discoloration of \#8 and \#9 had changed to a very mild grey, and the pulps continued to have normal responses to $\mathrm{CO}_{2}$ and electric pulp sensibility tests. A change in the diastema between \#8 and \#9 was also noticed and the mesial aspects of these teeth had an interproximal contact point re-established (Figs. 9 10, and 11).

This case was followed and maintained for more than one year with regular recalls every 3 months. His periodontal condition remained stable and both upper central incisors continued to have very mild grey discoloration with normal responses to pulp sensibility tests. This patient was referred for orthodontic treatment in July 2012 and this was completed in June 2014. After completion of orthodontic treatment a mild grey discolouration on both upper central incisors persisted (Figs. 12 and 13). The teeth continue to respond normal to pulp sensibility tests.

\section{Discussion}

The patient in this case report did not have any history of impact trauma to his upper central incisors. The only known trauma to the roots of the teeth exhibiting TTD was the meticulous radicular instrumentation of the deep $(9 \mathrm{~mm})$ periodontal pockets in September 2010 as part of the initial phase of periodontal treatment.

In most cases of TTD after transient radicular breakdown, the discoloration has appeared several weeks or a few months after a traumatic event. ${ }^{3,4,6-8,13}$ In this particular case, there was an interval of 5 months between periodontal instrumentation and the appearance of the grey/rosy discoloration.

Different biological events may have occurred in this case. Trauma from periodontal instrumentation with curettes or scaler tips may induce pulp hemorrhage through anatomical communications - such as via lateral root canals, dentinal tubules, accessory canals or the apical foramen. This instrumentation is a traumatic procedure and it may translocate periodontal microorganisms within the periodontal pocket external to the pulp, triggering some hemorrhagic events initially within the root canal and later within the pulp chamber inducing the discoloration. ${ }^{4}$ Cross-seeding of bacteria from one tissue to the other can also occur and this can happen in either direction - that is, from the root canal to the periodontium, or vice versa - through anatomical communication pathways. ${ }^{14,15}$ Reversible dental color changes are a result of spilling of blood and blood breakdown products into the tissue stroma at the interface between vital and ischemic pulp tissue in experimental tooth extraction/replantation studies. ${ }^{16}$

In this aggressive periodontitis case, TTD may be related to a wider root canal and larger pulp chamber in teenagers in contrast to the natural processes where calcification of the root canal system that occurs as patients age leads to smaller pulp spaces with more dentine protection. It is more likely to find smaller root canal systems in patients with chronic periodontitis leaving less chance of inducing trauma to the pulp. It is also possible that some accessory or lateral root canals may be wider 
in a younger patient, leaving more chances for microbiological products or hemorrhage from trauma to occur.

\section{Summary}

\begin{tabular}{|l|l|}
\hline Why is this case new information? & $\begin{array}{l}\text { To the best of the authors' knowledge } \\
\text { this is the first case report of transient } \\
\text { tooth discoloration after periodontal } \\
\text { instrumentation of teeth affected by } \\
\text { localized aggressive periodontitis. }\end{array}$ \\
\hline $\begin{array}{l}\text { What are the keys to the successful } \\
\text { management of this case? }\end{array}$ & $\begin{array}{l}\text { Proper diagnosis and periodontal, } \\
\text { endodontic and and a } \\
\text { multidisciplinary management of this } \\
\text { patient. }\end{array}$ \\
\hline $\begin{array}{l}\text { What are the primary limitations to } \\
\text { success in this case? }\end{array}$ & $\begin{array}{l}\text { A lack of complete resolution of tooth } \\
\text { discoloration. }\end{array}$ \\
\hline
\end{tabular}

\section{References}

1. Skoglund A, Tronstad L. Pulpal changes in replanted and autotransplanted immature teeth of dogs. $J$ Endod 1981;7:309-316.

2. Ne RF, Witherspoon DE, Gutmann JL. Tooth resorption. Quintessence Int 1999;30:9-25.

3. Andreasen FM. Pulpal healing after luxation injuries and root fracture in the permanent dentition. Endod Dent Traumatol 1989;5:111-131.

4. Andreasen FM. Transient apical breakdown and its relation to color and sensibility changes after luxation injuries to teeth. Endod Dent Traumatol 1986;2:9-19.

5. Auslander WP. Discoloration, a traumatic sequela. N Y State Dent J 1967;33:534-538.

6. Boyd KS. Transient apical breakdown following subluxation injury: a case report. Endod Dent Traumatol 1995;11:37-40.

7. Cohenca N, Karni S, Rotstein I. Transient apical breakdown following tooth luxation. Dent Traumatol 2003;19:289-291.

8. Malmgren B, Hubel S. Transient discoloration of the coronal fragment in intra-alveolar root fractures. Dent Traumatol 2012;28:200-204.

9. Armitage GC. Development of a classification system for periodontal diseases and conditions. Ann Periodontol 1999;4:1-6.

10. Lang NP, Bartold PM, Cullinam M et al. Consensus Report: Aggressive Periodontitis. Ann Periodontol 1999;4: 53

11. Haas AN, de Castro GD, Moreno T, et al. Azithromycin as an adjunctive treatment of aggressive periodontitis: 12-months randomized clinical trial. J Clin Periodontol 2008;35:696-704.

12. Guerrero A, Griffiths GS, Nibali L, et al. Adjunctive benefits of systemic amoxicillin and metronidazole in non-surgical treatment of generalized aggressive periodontitis: a randomized placebo-controlled clinical trial. J Clin Periodontol 2005;32:1096-1107.

13. Gonzalez OL, Vera J, Orozco MS, Mancera JT, Gonzalez KV, Malagon GV. Transient apical breakdown and its relationship with orthodontic forces: a case report. $J$ Endod 2014;40:1265-1267.

14. Abbott PV, Salgado JC. Strategies for the endodontic management of concurrent endodontic and periodontal diseases. Aust Dent J 2009;54 Suppl 1:S70-85.

15. Bergenholtz G, Lindhe J. Effect of experimentally induced marginal periodontitis and periodontal scaling on the dental pulp. J Clin Periodontol 1978;5:59-73.

16. Andreasen FM, Kahler B. Pulpal response after acute dental injury in the permanent dentition: clinical implications-a review. J Endod 2015;41:299-308. 
Author Correspondence: Julio C Rincon A The University of Western Australia, School of Dentistry, Oral Health Centre of Western Australia, 17 Monash Ave NEDLANDS. Western Australia 6009. Phone 61893467664 Fax: 61893467666 E mail: julio.rincon@uwa.edu.au

Submitted August 31, 2016; accepted for publication December 20, 2016.

\section{Figure 1.}

Clinical presentation of localized aggressive periodontitis (July 2010) baseline frontal view.

\section{Figure 2.}

Baseline Periodontal Chart (July 7, 2010).

Figure 3.

Periapical radiograph of \#3, \#4, and \#5 at baseline. (June 2010)

\section{Figure 4.}

Periapical radiograph of the upper incisors showing moderate horizontal bone loss. (June 2010)

\section{Figure 5.}

Periapical radiograph of the lower incisors showing moderate horizontal bone loss. (June 2010)

\section{Figure 6.}

Frontal view after periodontal review (November 2010).

Figure 7.

Grey/rosy discoloration of both upper central incisors (Frontal view).(February 2011)

\section{Figure 8.}

Grey/rosy discoloration occlusal view of both central incisors (February 2011).

\section{Figure 9.}

Frontal view six months after initial discoloration was noted (August 2011).

\section{Figure 10.}

Periapical radiograph of \#3 and \#4, showing healing of the mesial angular bone defect on \#3. (August 2011)

\section{Figure 11.}

Periapical radiograph of \#8 and \#9 showing healing of alveolar bone and closure of interproximal diastema. (August 2011)

\section{Figure 12.}

Labial clinical presentation after completion of orthodontic treatment. (June 2014) 


\section{Figure 13.}

Oclusal clinical presentation after completion of orthodontic treatment. (June 2014)

Key Findings: Transient tooth discoloration may be caused by trauma from periodontal instrumentation. This is the first case report of TTD in an aggressive periodontitis patient. 


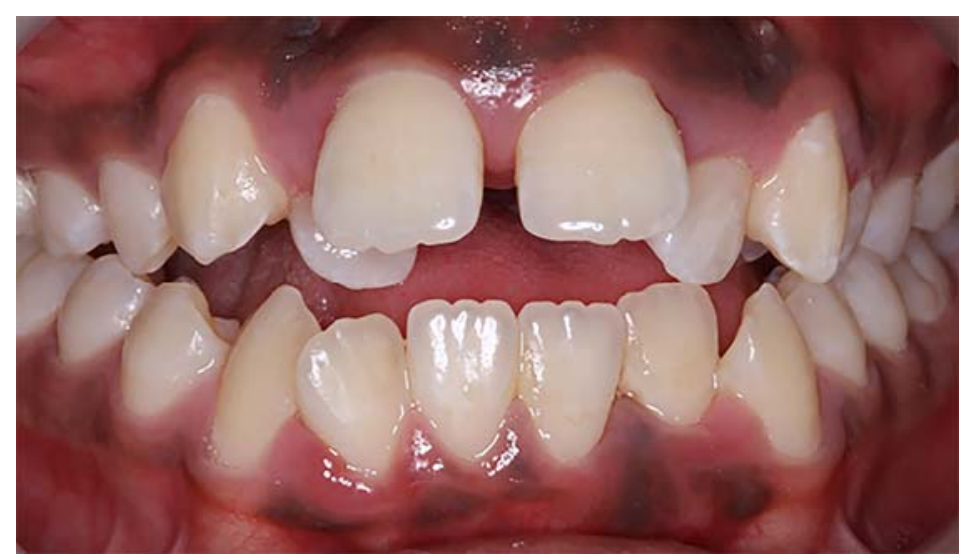




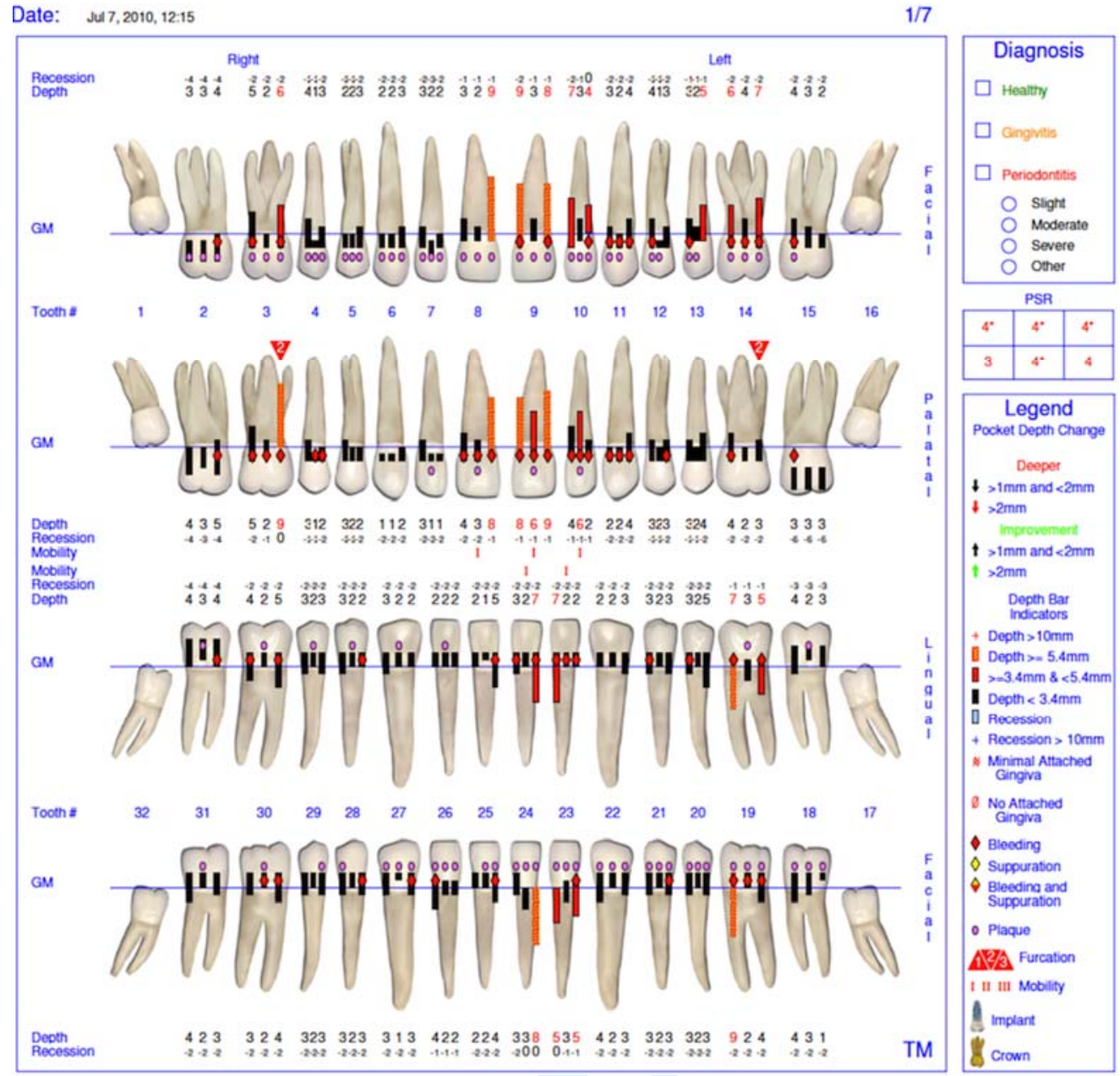




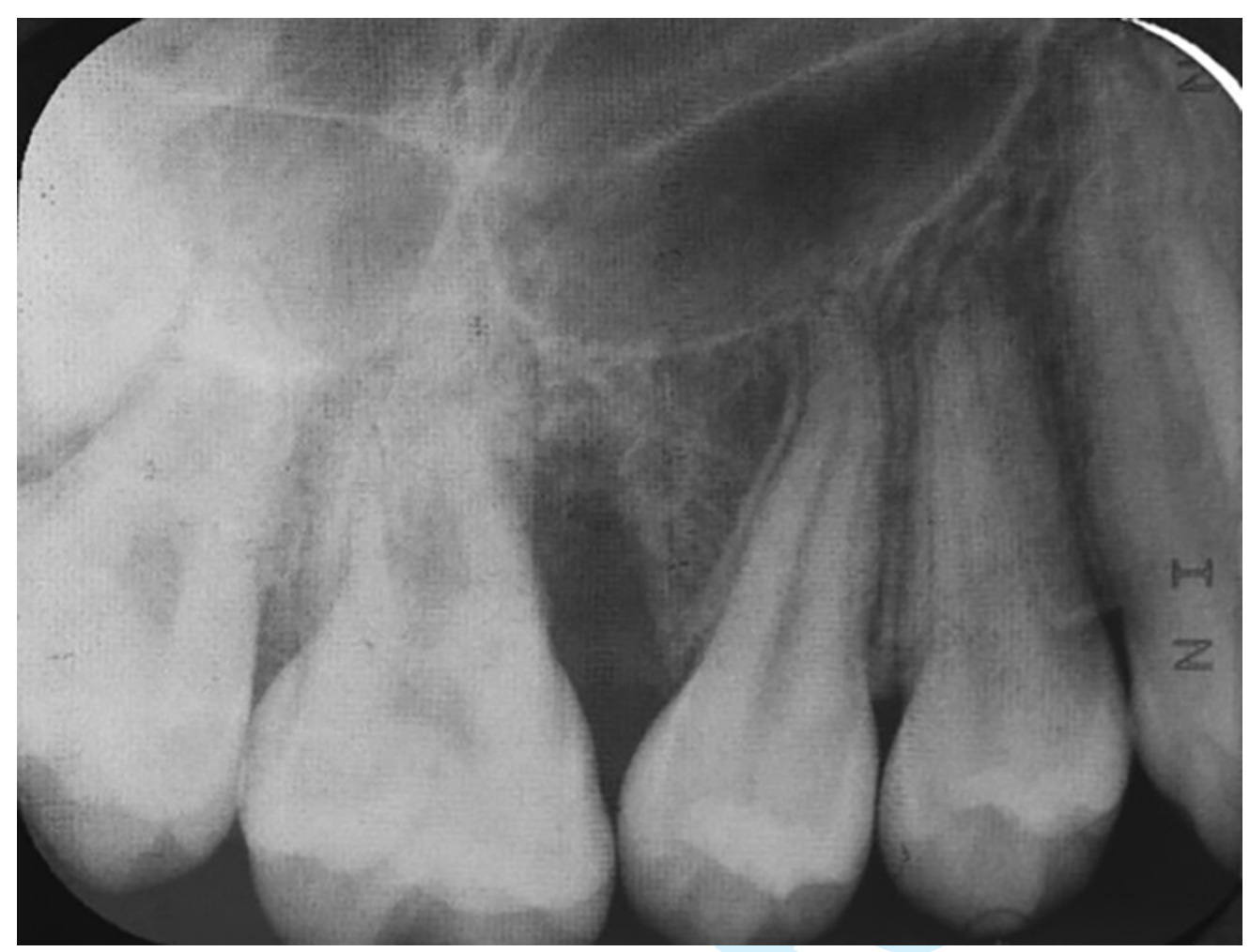




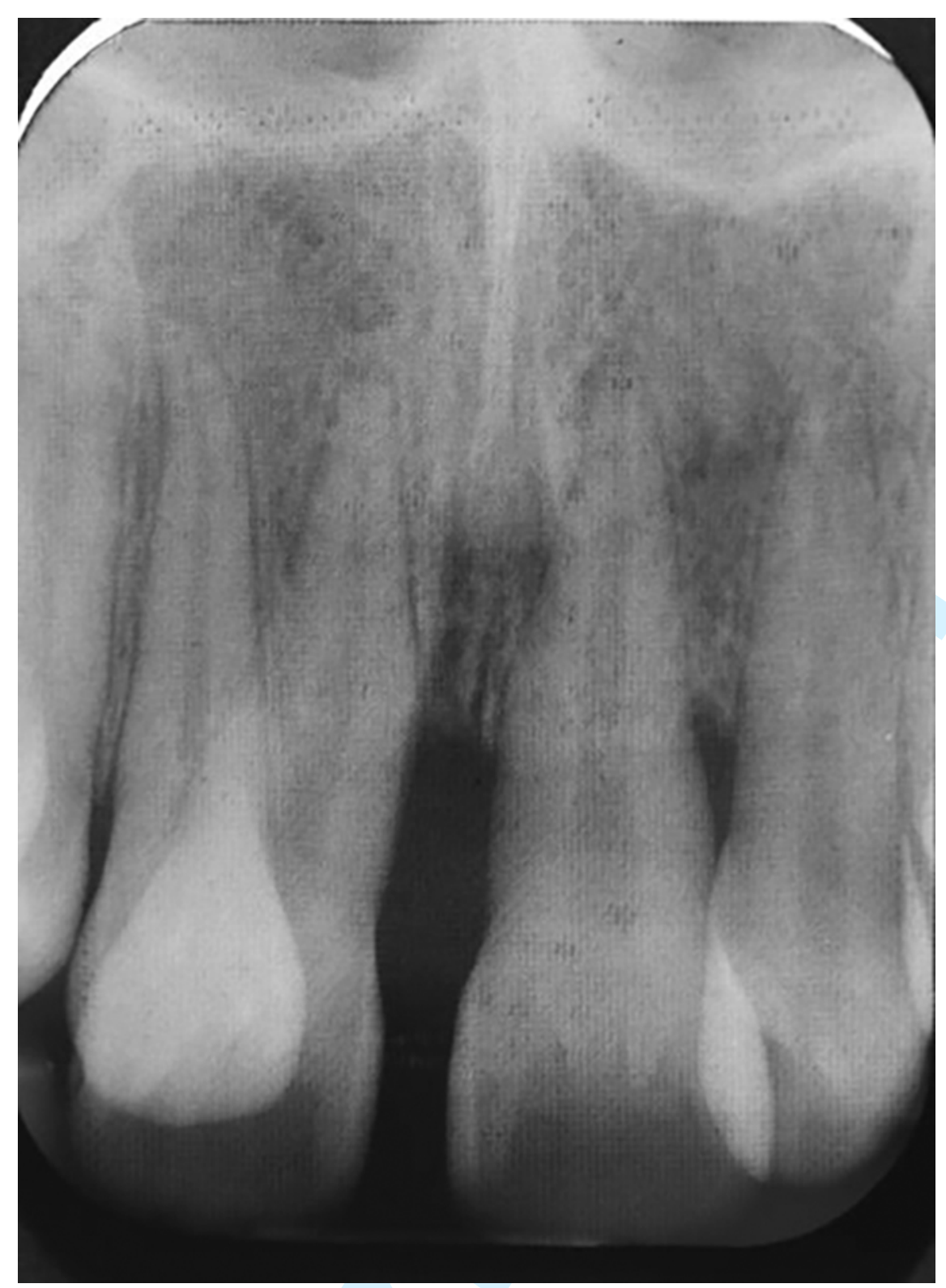




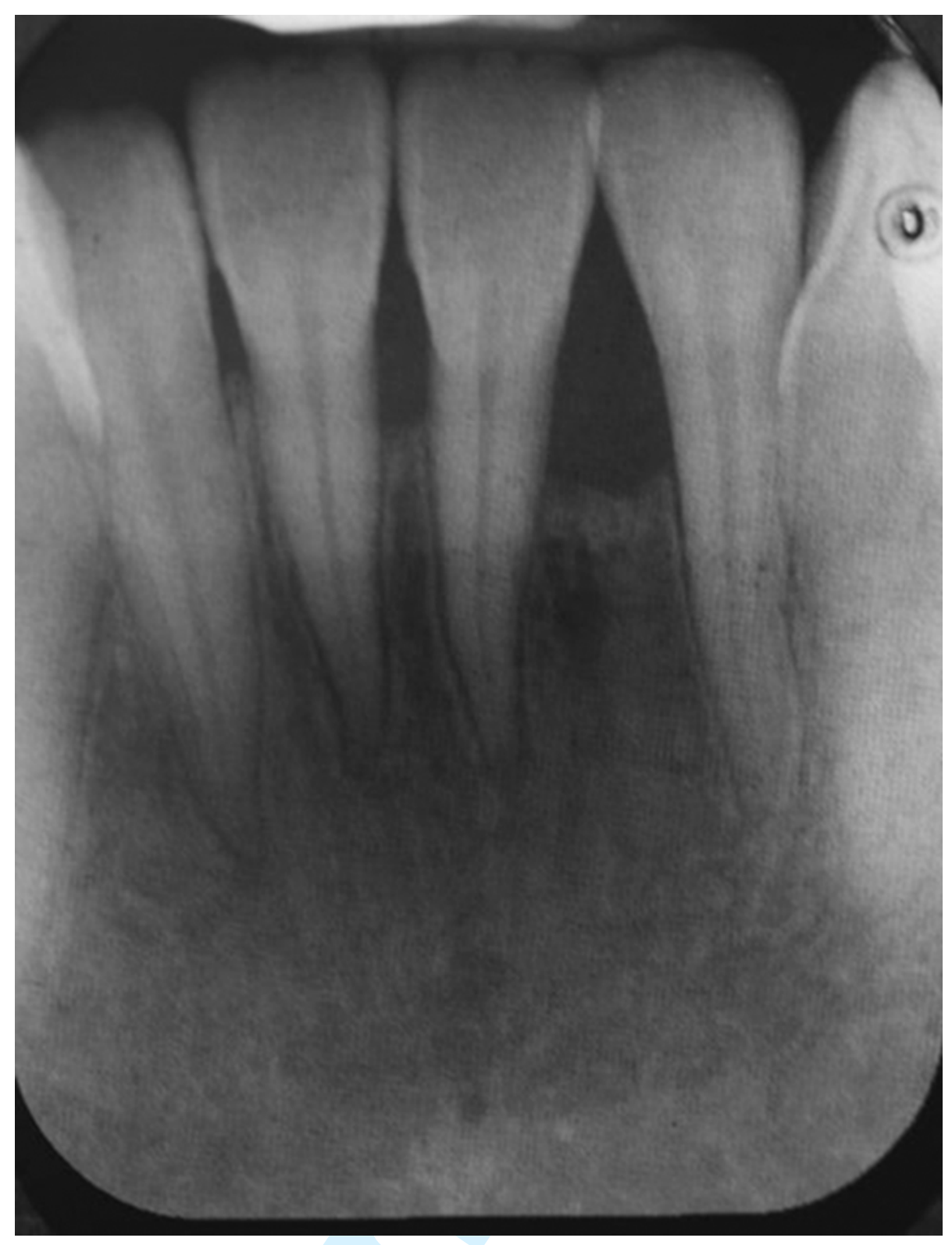




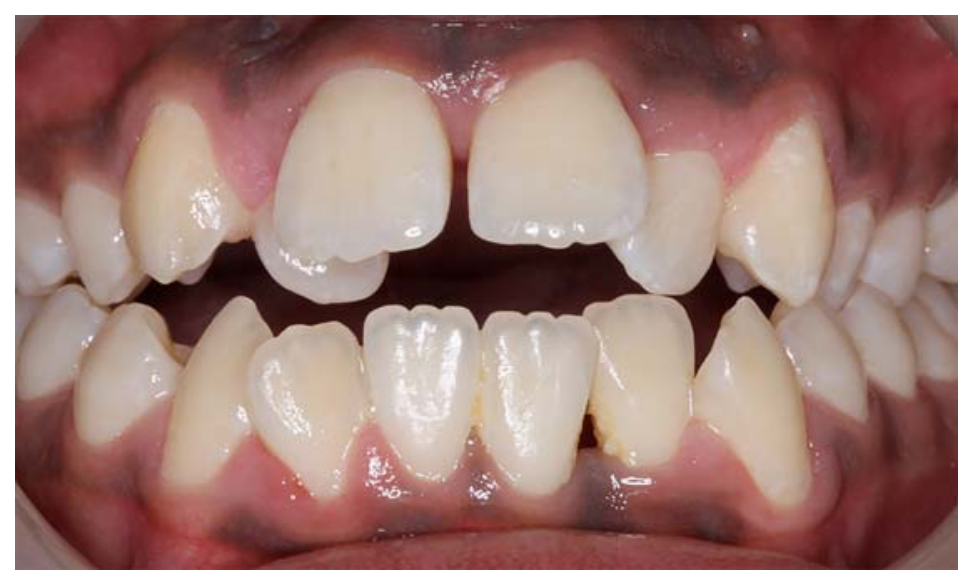




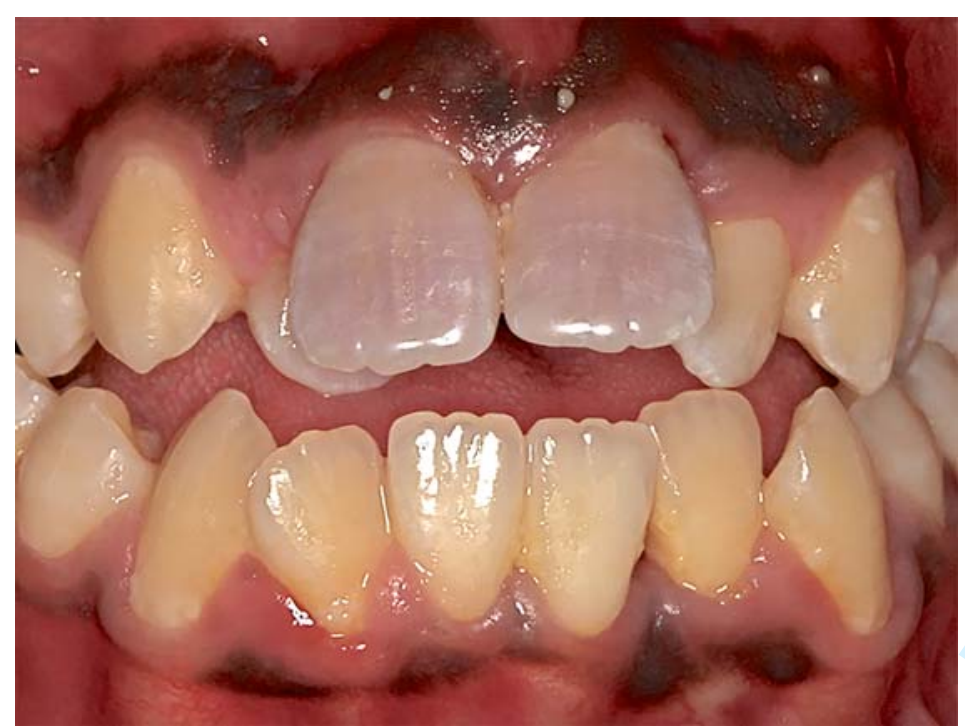




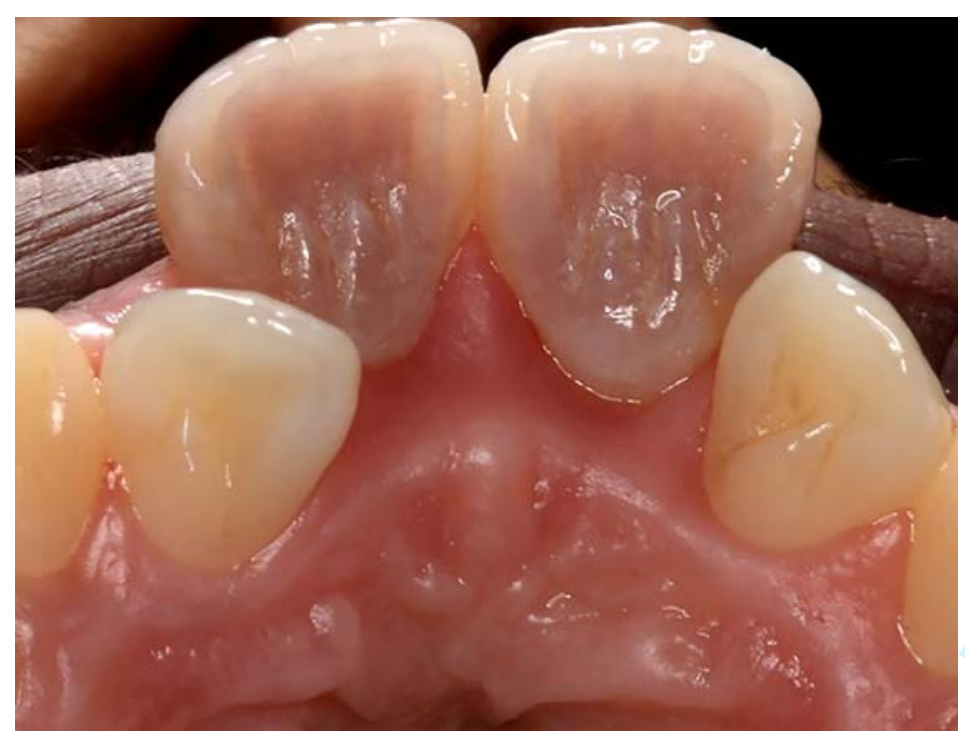




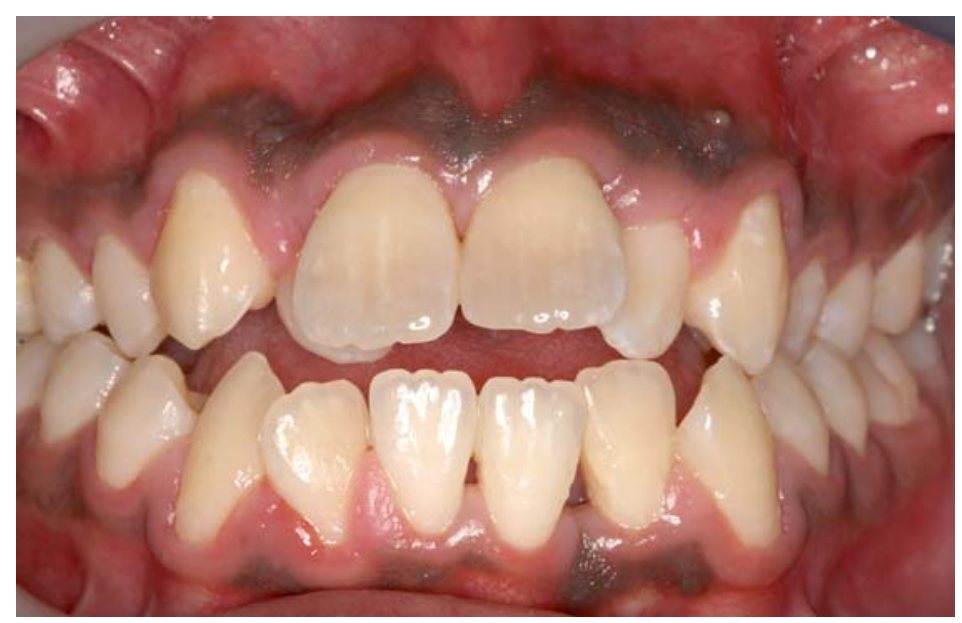




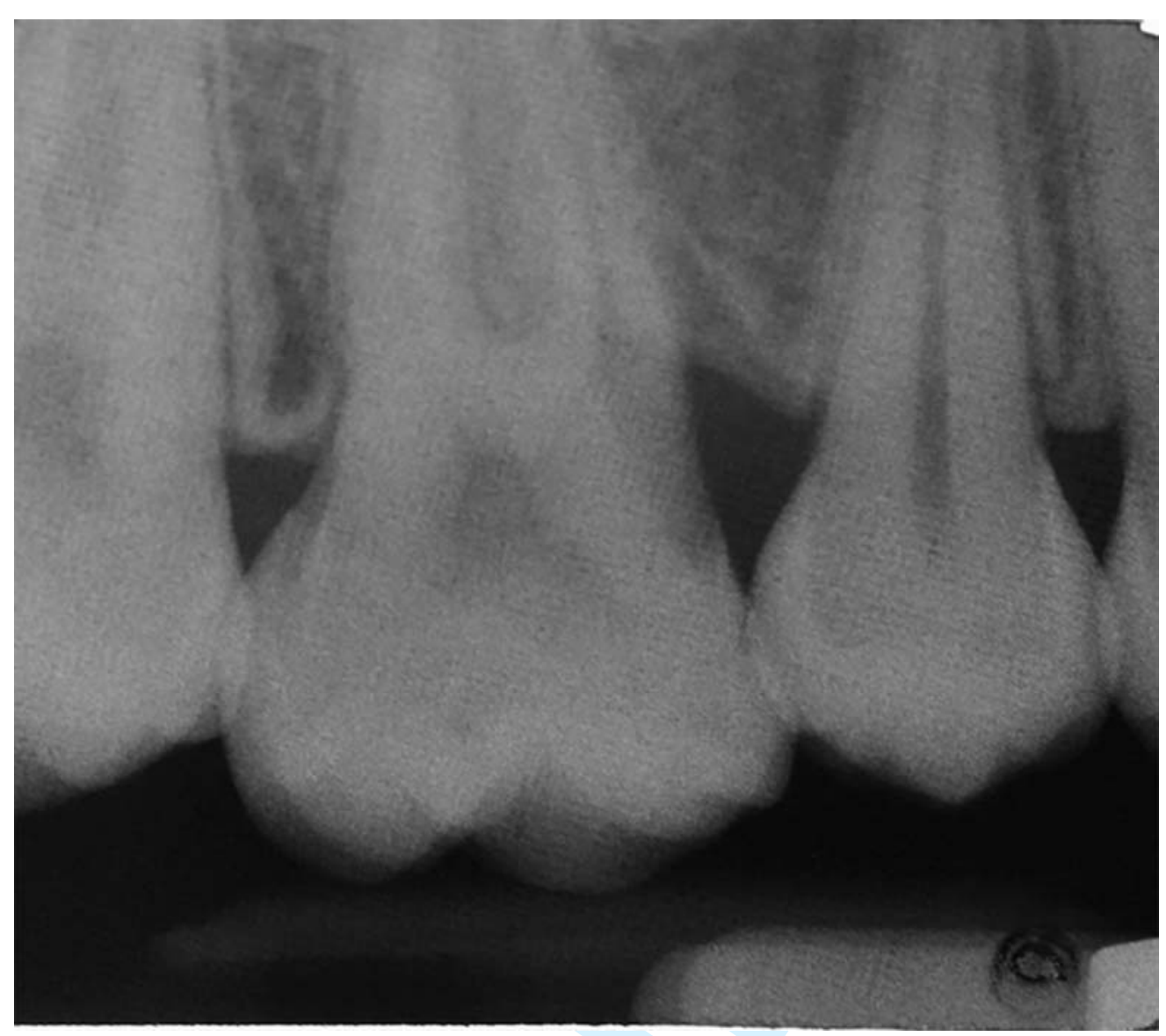




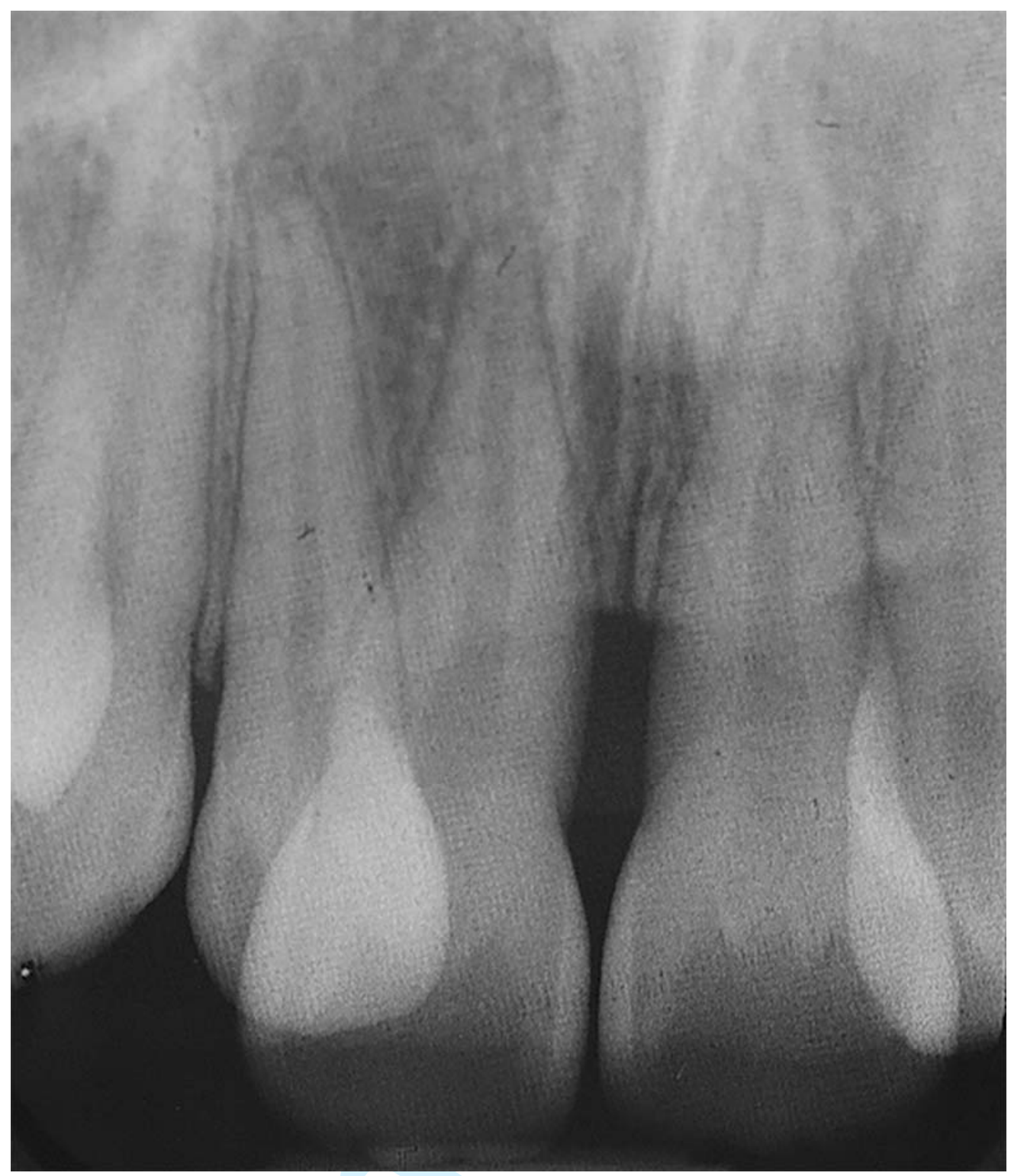




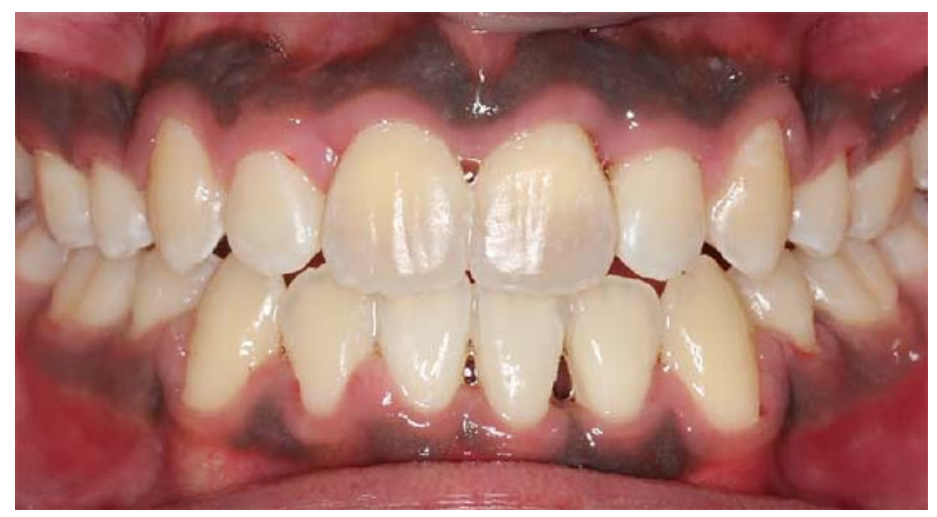




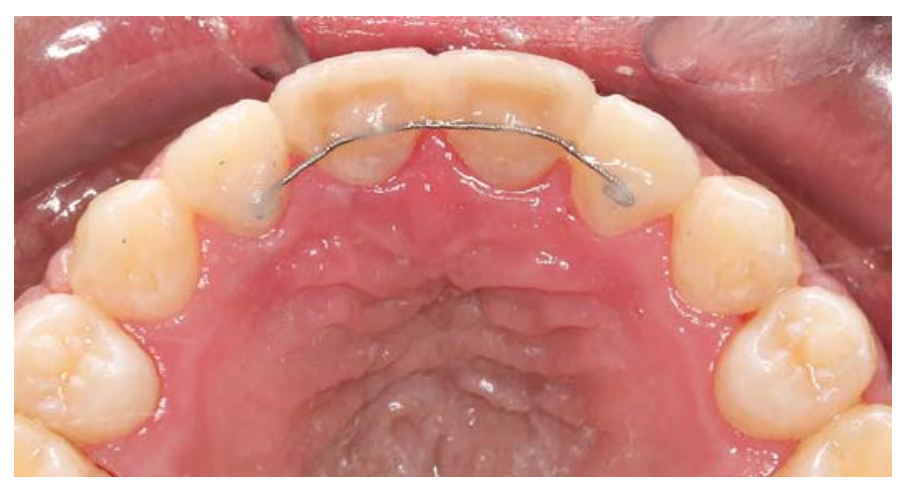

